\title{
Child Labor issues in Nepal
}

\author{
Sunil Kumar Joshi
}

Child labor has been one of the most sensitive and widely worked and discussed issues in Nepal. The constant involvement of various government agencies together with non-governmental support in addressing diverse issues of child labor has culminated some significant changes. The promulgation of the Child Labor Act 1992 and ratification of ILO convention No. 138 and 182 have been major stepping stones in addressing this precarious problem.

Child labor is illegal and a criminal offense, but the actuality in practice and the text resonate differently. The involvement of child labor is widely distributed in both formal and informal sectors but the informal sector mostly hidden beyond the horizon has been a major breeding ground for rampant child labor practices. The Nepal Labor Force Survey (2008) estimates 40.4 per cent of child population falls under economically active population and among these working children almost 51 per cent fall under child labor category.

The roots of the problem of child labor in Nepal lie deep in the larger socio-economic and cultural system of the country. Sometimes the cause of the problem is assigned to the fact that $90 \%$ of the population lives in the rural areas and sometimes to dependence of $81 \%$ population on subsistence agriculture. Whatever may be the cause of child labor, it is stigmatic to live with the distinction of having a great number of child population working as child laborers in the country. More importantly, the persistence of the problem reinforces the cycle of disadvantage resulting from poverty, illiteracy and lack of viable economic alternatives. This situation not only deprives the children from their fundamental rights but also impairs the future of the child laborers as well as that of the society and nation at large.

The children exposed to hazardous working conditions often find themselves working at minimum standards with excessive workloads jeopardizing their overall well-being. The lack of safety and hygiene, poor physical conditions and burden of repetitive job in absence of any standard occupational safety and health practices exposes children affecting their physical, mental and over all development. The gender differences at work contributing to unequal pay, sexual exploitation, debt bondage, and lack of access to health services, education and opportunities are some of the tips of iceberg relating to child labor phenomenon in Nepal.

Elimination of all forms of child labor is a long-term goal, the achievement of which depends upon the overall economic development of the country. Yet, the challenge of protecting children from the most hazardous forms of labor should be tackled as a matter of urgency and priority. Child labor related ILO Conventions (No. 138 and 182) and recommendation (No 190), both require the ratifying states to take immediate and effective measures to prohibit and eliminate hazardous/ worst forms of child labor. For this purpose, it is necessary to identify and locate the hazardous forms of child labor, workplaces, and processes in consultation with concerned stakeholders, employers' and workers' organizations. Likewise, the exposure of children to such places and processes should be strictly monitored. However, any measures to monitor and eliminate hazardous forms of child labor require the identification and high prioritization of such works.

The Government of Nepal has expressed its firm commitment to combat both general and worst forms of child labor, which is now being reflected in national policies and programmes. Government of Nepal is currently implementing a National Master Plan on Child Labor, which aims at eliminating all forms of child labor by 2014. Given the commitments and efforts made by Government of Nepal, ILO has chosen Nepal to be one of the countries implementing Time-Bound Programme for the Elimination of Worst Forms of Child Labor. The schedule of Child Labor (Prohibition and Regularization) Act 2000 has identified a number of works and sectors as hazardous work. However, it has been felt that the list in the schedule is too inclusive and not amenable to effective enforcement as it does not identify the specific jobs or work processes, which are hazardous.

It is imperative to create awareness and alter behavior and practices safeguarding interest and well-being of children working in vulnerable conditions. It requires serious commitment and enforcement of best practices in combating the child labor practice. A clearer government policy with implementation plans and follow-up mechanisms with regard to child labor must be in place through effective government initiatives. Strong co-ordination among various central and local governments must be developed. For this, capacity of respective agencies should be enhanced. Codes of conduct by employers can also play a vital role in changing attitude of the people towards child labor.

Without serious attempts to implement and enforce the existing laws on child labor and related issues, it is difficult to point out the exact amendments required. So, effective implementation and enforcement should take priority over new legislation and amendments. Clear divisions of responsibility, a culture of accountability, an end to impunity, hassle free and efficient justice systems are fundamental prerequisite for effective legal enforcement.

It is an uphill task to observe visible changes overnight but an effort for so would help to make that day approach nearer. This effort of disseminating information and bringing forward real and emerging issues will open an avenue for dialogue on required changes with responsibilities and obligation of all concerned stakeholders. The bottom line still remains the same, child labor can be managed and working conditions can be improved, but it requires a serious commitment from all of us. 